\title{
Evaluation of the Effect of Topiroxostat on Renal Function in Patients with Hyperuricemia: STOP-C Study, a Retrospective Observational Cohort Study
}

\author{
Eiji Tamiya ${ }^{1} \cdot$ Haruyo Yamashita ${ }^{1} \cdot$ Tomosato Takabe $^{1} \cdot$ Takahiro Matsumoto $^{1} \cdot$ Jun Kajihara $^{1} \cdot$ Shouichi Yamamoto $^{1}$. \\ Tatsuji Kanoh $^{1} \cdot$ Hikaru Koide $^{2} \cdot$ Tohru Minamino $^{3}$
}

Accepted: 30 December 2021 / Published online: 29 January 2022

(c) The Author(s) 2022

\begin{abstract}
Background Serum uric acid-lowering therapy is associated with maintaining renal function.

Objective We aimed to retrospectively evaluate renal function and serum uric acid in patients with hyperuricemia who received topiroxostat for over a year.

Methods Medical records of patients from 1 January, 2015 to 31 October, 2019 in our hospital were used. From the medical records, data of 100 patients with hyperuricemia treated with topiroxostat were extracted (67:33 male:female). The primary endpoints were changes in serum creatinine level and estimated glomerular filtration rate at 12 months after topiroxostat administration. The secondary endpoints were changes in serum creatinine, serum uric acid, and estimated glomerular filtration rate before and after topiroxostat administration.

Results The study mainly involved elderly individuals ( $77.2 \pm 9.5$ years). Forty-four patients administered uric acid-lowering drugs were switched to topiroxostat. After 12 months, the serum creatinine level and estimated glomerular filtration rate showed no significant changes from baseline; however, the serum uric acid level significantly decreased. The estimated glomerular filtration rate significantly decreased during the 6 months before topiroxostat administration $(p<0.001)$, but showed no significant change at 6 months after topiroxostat administration $(p=0.849)$.

Conclusions This study revealed that topiroxostat use not only reduced the serum uric acid level but also maintained renal function in elderly patients with hyperuricemia in daily clinical practice.
\end{abstract}

Eiji Tamiya

eiji.tamiya.hua@gmail.com

1 Department of Cardiology, Koto Hospital, 6-8-5, Ojima, Koto-ku, Tokyo, Japan

2 Department of Internal Medicine, Koto Hospital, Tokyo, Japan

3 Department of Cardiovascular Medicine, Juntendo University Graduate School of Medicine, Tokyo, Japan 


\section{Key Points}

Topiroxostat, administered for more than 1 year, did not increase serum creatinine and retained estimated glomerular filtration rate in patients with hyperuricemia up to chronic kidney disease stage G4, including $66 \%$ of patients aged $\geq 75$ years. The mean serum uric acid decreased significantly within 3 months after topiroxostat administration, reaching $\leq 6.0 \mathrm{mg} / \mathrm{dL}$, as recommended by the guidelines.

The estimated glomerular filtration rate decreased significantly from 6 months before topiroxostat administration to baseline, but the decline in the estimated glomerular filtration rate was suppressed at 6 months after topiroxostat administration.

Topiroxostat may be a useful uric acid-lowering agent for elderly patients with hyperuricemia in daily clinical practice.

\section{Introduction}

Increased uric acid (UA) levels in the blood or hyperuricemia is defined as $>7.0 \mathrm{mg} / \mathrm{dL}$ in Japan, causes gouty arthritis and gouty tophus, as urate crystallizes due to low solubility in water [1]. However, hyperuricemia is not only associated with gout but also with a variety of cardiometabolic diseases, including hypertension, chronic kidney disease (CKD), hypertriglyceridemia, obesity, atherosclerotic heart disease, and metabolic syndromes [2-4].

Changes in the UA levels can result in multiple physiological effects that can impair renal function [5]. Previous epidemiological studies involving the general population have shown an independent effect of hyperuricemia on the risk of renal outcomes [6-10].

An association with CKD has been previously reported in patients with asymptomatic hyperuricemia [11]. According to the Japanese guidelines, the treatment of hyperuricemic patients with CKD requires a strict control of the UA level [12], as high UA levels and impaired renal function are interrelated, exacerbating each other. Elderly patients with hyperuricemia are often encountered in clinical practice, and these patients generally have decreased renal function at the start of treatment $[7,13,14]$.

Meta-analyses with xanthine oxidoreductase (XOR) inhibitors, such as allopurinol and febuxostat, have shown that UA-lowering treatment in CKD may inhibit the progression of renal function decline [6, 15]. However, it is necessary to reduce the dose of allopurinol in patients with impaired renal function due to the accumulation of allopurinol metabolites [12]. The use of febuxostat in hyperuricemic patients with comorbid cardiovascular disease is controversial owing to concerns of cardiovascular safety [16]. Topiroxostat, a novel nonpurine XOR inhibitor developed in Japan, has been reported to significantly reduce the urinary albumin/creatinine ratio in patients with hyperuricemia associated with renal impairment without changing dosage $[17,18]$. One of the merits of topiroxostat is that there is no need to consider topiroxostat dose adjustment depending on renal function.

We have often found that hyperuricemic patients treated with topiroxostat showed improved or maintained estimated glomerular filtration rate (eGFR) and serum creatinine $(\mathrm{sCr})$ levels, along with a reduction in serum UA (sUA). Although some studies have examined the relationship between XOR inhibitors and renal function in clinical practice, few studies have focused on the relationship between $\mathrm{sCr}$ and UA-lowering therapy. We conducted a retrospective $\underline{\text { Study of }}$ TOPiroxostat on serum $\underline{\text { Creatinine }}$ levels in patients with hyperuricemia (STOP-C) to investigate the effects of topiroxostat administration on renal function in hyperuricemic patients with impaired renal function in a real-world setting.

\section{Methods}

\subsection{Study Design and Patient Population}

The STOP-C study was a single-center, open, retrospective cohort study conducted at Koto Hospital. We assessed the clinical data extracted from the medical records from 1 January, 2015 to 31 October, 2019. The inclusion criteria for data extraction were as follows: (1) patients taking topiroxostat for at least 1 year and (2) patients aged 20 years or older on the first day of administration with topiroxostat. Patients who had the following conditions at the start of treatment with topiroxostat were excluded: (1) serious liver or kidney disease; (2) hemodialysis or kidney transplantation; and (3) a concurrent malignant tumor. The following patients were also excluded: (4) patients taking other UA-lowering drugs additionally to topiroxostat. Topiroxostat was administered considering the patient's clinical course, without particular limitations.

The study was approved by the Ethics Committee of Koto Hospital in November 2019. In conducting the study, the "Ethical Guidelines for Medical Research Involving Human Subjects" were observed. The information obtained in this study was anonymized and treated with caution to protect the confidentiality of personal information. 


\subsection{Evaluation Parameters}

Baseline was considered the first day of topiroxostat treatment. We collected baseline information, including age, sex, and concomitant diseases (hypertension, dyslipidemia, type 2 diabetes mellitus, CKD, atrial fibrillation, and cardiovascular disease), and laboratory parameters, including aspartate transaminase, alanine transaminase, high-density lipoprotein cholesterol, low-density lipoprotein cholesterol, triglycerides, glycated hemoglobin, N-terminal pro-brain natriuretic peptide, C-reactive protein, blood urea nitrogen, sCr, sUA, and urinary protein. Serum creatinine and sUA levels in patients who visited the hospital 6 months before baseline only after 1 January, 2015 were also collected. If there was no height record at baseline, the height closest to the baseline was supplemented during the 36 months from baseline. Body weight at baseline and 3, 6, 9, 12, 24, and 36 months from baseline, daily dose of topiroxostat, and concomitant use of other medications for hypertension, type 2 diabetes, or dyslipidemia were also investigated.

Body mass index was calculated by dividing body weight $(\mathrm{kg})$ by height $(\mathrm{m})$ squared. Estimated glomerular filtration rate was calculated using the following equation: eGFR $(\mathrm{mL} /$ $\left.\mathrm{min} / 1.73 \mathrm{~m}^{2}\right)=194 \times \mathrm{sCr}^{1.094} \times \mathrm{age}^{-0.287}[\times 0.739$ in the case of women] [19].

\subsection{Study Endpoints}

The primary endpoints were changes in $\mathrm{sCr}$ and eGFR from the baseline to 12 months. The secondary endpoints were changes in sCr, eGFR, and sUA at each timepoint after baseline. The exploratory endpoints were considered as the achievement rate of sUA $\leq 6.0 \mathrm{mg} / \mathrm{dL}$ at 6 months after the administration of topiroxostat. Changes in eGFR 6 months before and after baseline were also compared as the degree of progression of renal dysfunction.

As an evaluation of safety, adverse events from patient medical information for which a relationship to topiroxostat could not be ruled out were investigated as adverse drug reactions. Additionally, changes in the levels of aspartate transaminase, alanine transaminase, high-density lipoprotein cholesterol, low-density lipoprotein cholesterol, triglycerides, glycated hemoglobin, $\mathrm{N}$-terminal pro-brain natriuretic peptide, C-reactive protein, and blood urea nitrogen after administration of topiroxostat were evaluated with an eye towards safety of the patient.

\subsection{Statistical Analysis}

The target sample size was not designed because it was a single-center retrospective observational study; however, the number of patients who could be accumulated in our hospital was estimated to be at least 100. Statistical analysis was performed using SAS version 9.2 (SAS Institute Japan Ltd., Tokyo, Japan). Continuous variables with a normal distribution were expressed as the mean \pm standard deviation, and data with a non-normal distribution were expressed as the median and a four-quartile range. The differences in continuous variables were expressed as mean \pm standard error. Changes in clinical examination values between the baseline and post-baseline periods for the primary and secondary endpoints were compared using an independent sample t-test for normal distribution values and a nonparametric Mann-Whitney $U$ test for non-normally distributed values. In all statistical analyses, two-sided $p$ values of $<0.05$ were considered statistically significant without considering multiplicity. Changes in eGFR between baseline and 6 months after treatment with topiroxostat or between 6 months before baseline and baseline were compared using an independent sample $t$ test.

\section{Results}

\subsection{Patient Background}

A total of 104 patients were enrolled in the study. Of these, four patients were excluded from the analysis because of duplicate entries, violation of exclusion criteria 3 or 4 , or failure to meet inclusion criteria 1. A total of 100 patients were included in the analysis, and their backgrounds are presented in Table 1. No special restrictions were placed on topiroxostat use; however, patients included in the analysis were markedly elderly, with an average age of $77.2 \pm 9.5$ years $(50-95$ years). The prevalence of complications included $95 \%$ hypertension, $73 \%$ CKD, and $46 \%$ atrial fibrillation. Estimated glomerular filtration rate over CKD stage $3\left(<60 \mathrm{~mL} / \mathrm{min} / 1.73 \mathrm{~m}^{2}\right)$ accounted for $84 \%$ of patients. Other UA-lowering drugs were administered in 44 patients (44.0\%) before topiroxostat treatment: allopurinol in 30 patients (mean dose, $108.3 \pm 32.4 \mathrm{mg}$ ), febuxostat in 12 patients $(16.7 \pm 11.5 \mathrm{mg})$, and benzbromarone in two patients $(50.0 \mathrm{mg})$; in 56 patients $(56.0 \%)$, hyperuricemia was untreated at baseline.

All patients received topiroxostat for up to 12 months, and 51 patients received topiroxostat for up to 36 months. The daily dose of topiroxostat was $50.0 \pm 18.3 \mathrm{mg}$ at baseline but increased to $74.4 \pm 35.1 \mathrm{mg}$ at 6 months and $90.4 \pm 41.0 \mathrm{mg}$ at 12 months, and was maintained at $101.9 \pm 48.1 \mathrm{mg}$ at 24 months and $105.5 \pm 48.0 \mathrm{mg}$ at 36 months.

\subsection{Changes in $\mathrm{sCr}$ and eGFR}

Serum creatinine decreased slightly in all patients, from $1.15 \pm 0.27 \mathrm{mg} / \mathrm{dL}$ at baseline to $1.14 \pm 0.29 \mathrm{mg} / \mathrm{dL}$ at 12 months, without a significant change ( $p=0.653$, Fig. 1A), 
Table 1 Patient backgrounds

\begin{tabular}{lll}
\hline Parameter & $N=100$ & $(\%)$ \\
\hline Male & 67 & $(67.0)$ \\
Age (years), mean \pm SD & $77.2 \pm 9.5$ & \\
$\geq 50$ and $<75$ & 34 & $(34.0)$ \\
$\geq 75$ and $<96$ & 66 & $(66.0)$ \\
BMI $\left(\mathrm{kg} / \mathrm{m}^{2}\right)$, mean $\pm \mathrm{SD}$ & $24.1 \pm 4.5$ \\
Hypertension & 95 & \\
Dyslipidemia & 87 & $(95.0)$ \\
Type 2 diabetes mellitus & 47 & $(87.0)$ \\
Chronic kidney disease & 73 & $(47.0)$ \\
Atrial fibrillation & 46 & $(73.0)$ \\
Cardiovascular disease & 56 & $(46.0)$ \\
Serum creatinine $(\mathrm{mg} / \mathrm{dL})$, mean $\pm \mathrm{SD}$ & $1.15 \pm 0.27$ \\
eGFR (mL/min/1.73 $\left.\mathrm{m}^{2}\right)$, mean $\pm \mathrm{SD}$ & $46.8 \pm 15.3$ \\
CKD stage & & \\
G1 & 2 & \\
G2 & 14 & \\
G3a & 31 & $(2.0)$ \\
G3b & 46 & $(31.0)$ \\
G4 & 7 & \\
Serum uric acid $(\mathrm{mg} / \mathrm{dL})$, mean $\pm \mathrm{SD}$ & $7.01 \pm 1.58$ \\
BUN (mg/dL), mean $\pm \mathrm{SD}$ & $20.8 \pm 6.6$ \\
\hline
\end{tabular}

CKD stage: eGFR $\geq 90$ in $\mathrm{G} 1,<90$ to $\geq 60$ in $\mathrm{G} 2,<60$ to $\geq 45$ in $\mathrm{G} 3 \mathrm{a},<45$ to $\geq 30$ in $\mathrm{G} 3 \mathrm{~b},<30$ to $\geq 15$ in $\mathrm{G} 4$

CKD stages were in accordance with the 2012 KDIGO guidelines (Levin A, Stevens PE. Summary of KDIGO 2012 CKD guidelines: behind the scenes, need for guidance, and a framework for moving forward. Kidney Int. 2014;85:49-61.)

$B M I$ body mass index, $B U N$ blood urea nitrogen, $C K D$ chronic kidney disease, $e G F R$ estimated glomerular filtration rate, $S D$ standard deviation

and eGFR in all patients slightly but not significantly increased from $46.8 \pm 15.3 \mathrm{~mL} / \mathrm{min} / 1.73 \mathrm{~m}^{2}$ at baseline to $47.1 \pm 15.9 \mathrm{~mL} / \mathrm{min} / 1.73 \mathrm{~m}^{2}$ at 12 months $(p=0.474$, Fig. 1B). The maintenance effect of topiroxostat on renal function was also observed in patients aged over 75 years as well as in patients aged under 75 years (Fig. 1A, B). The eGFR for 12 months was also maintained at each CKD stage (Table 2).

For 82 patients in whom sCr levels were measured 6 months before baseline, at baseline, and at 6 months after treatment with topiroxostat, the change in eGFR from 6 months before topiroxostat administration significantly decreased by $3.45 \pm 0.72 \mathrm{~mL} / \mathrm{min} / 1.73 \mathrm{~m}^{2}(p<0.001)$ from $50.74 \pm 15.74 \mathrm{~mL} / \mathrm{min} / 1.73 \mathrm{~m}^{2}$, but the change in eGFR after topiroxostat administration was a nonsignificant decrease of $0.18 \pm 0.94 \mathrm{~mL} / \mathrm{min} / 1.73 \mathrm{~m}^{2}$ from $47.29 \pm 15.82 \mathrm{~mL} /$ $\min / 1.73 \mathrm{~m}^{2}(p=0.849$, Fig. $2 \mathrm{~A})$, and the decline of eGFR after topiroxostat administration was suppressed $(p=0.005$, Fig. 2B).
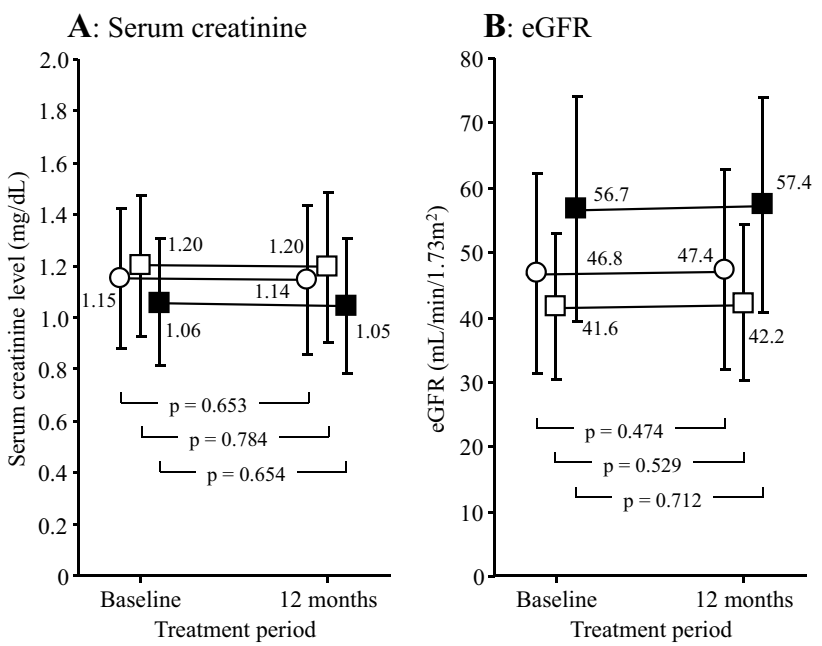

Fig. 1 Changes in serum creatinine (A) and estimated glomerular filtration rate [eGFR] (B) before and after 12 months of topiroxostat administration. Open circle, open square, and closed square indicate "all patients", "patients over 75 years old", and "patients under 75 years old", respectively. Mean \pm standard deviation

Table 2 Change in estimated glomerular filtration rate based on CKD stages before and after administration of topiroxostat

\begin{tabular}{llll}
\hline CKD stage & Baseline & 12 months & $p$ value \\
\hline $\mathrm{G} 1 / \mathrm{G} 2(n=16)$ & $74.2 \pm 12.3$ & $70.9 \pm 13.4$ & 0.333 \\
$\mathrm{G} 3 \mathrm{a}(n=31)$ & $50.8 \pm 14.1$ & $52.1 \pm 19.0$ & 0.371 \\
$\mathrm{G} 3 \mathrm{~b}(n=46)$ & $37.8 \pm 14.5$ & $39.2 \pm 17.6$ & 0.173 \\
$\mathrm{G} 4(n=7)$ & $25.0 \pm 13.4$ & $26.4 \pm 15.5$ & 0.538 \\
\hline
\end{tabular}

Unit is $\mathrm{mL} / \mathrm{min} / 1.73 \mathrm{~m}^{2}$; mean \pm standard deviation

$C K D$ chronic kidney disease
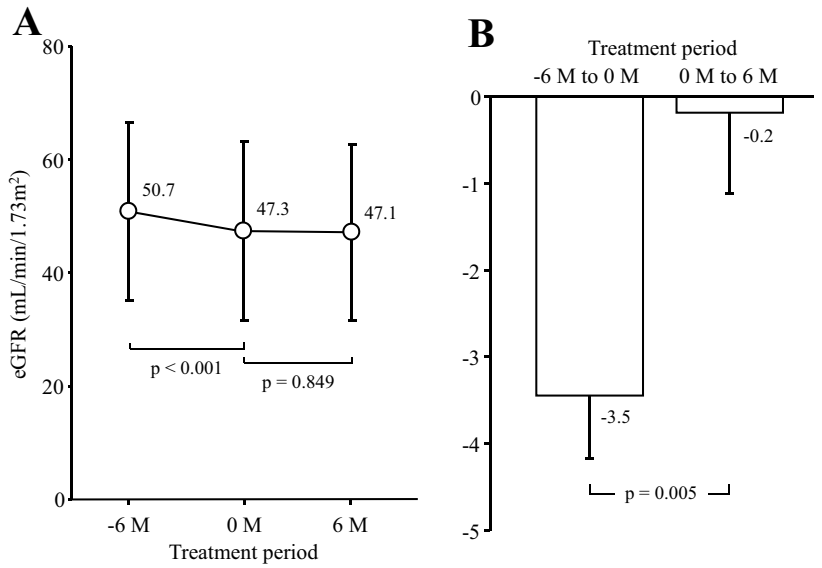

Fig. 2 Changes in estimated glomerular filtration rate (eGFR) before and after 6 months of topiroxostat treatment (A) and differences between the two timepoints (B). Changes over time are expressed as the mean \pm standard deviation, and differences are expressed as mean \pm standard error. $M$ months 


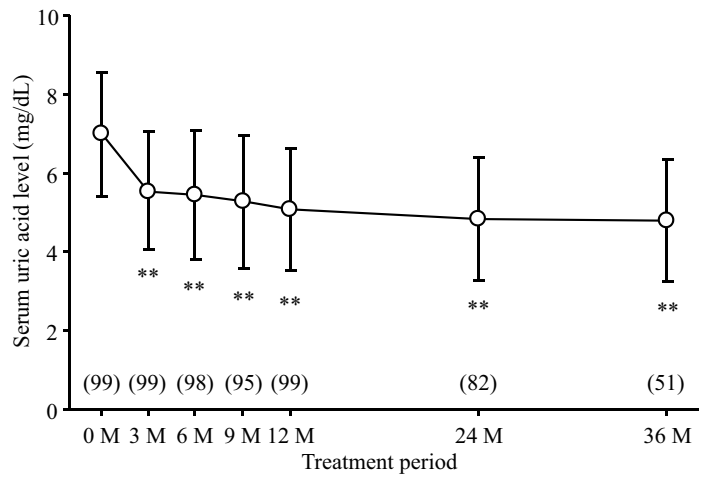

Fig. 3 Changes in serum uric acid level in response to treatment with topiroxostat. Each timepoint was compared to the baseline. Figures in parentheses indicate the number of patients. Mean \pm standard deviation. $M$ months, $* * p<0.001$

\subsection{Change in sUA}

The changes in sUA levels are shown in Fig. 3 and Table 3. The sUA level was significantly decreased by the administration of topiroxostat, and the decrease in sUA level was maintained even after 36 months (Fig. 3).

Among 69 patients with sUA $>6.0 \mathrm{mg} / \mathrm{dL}$ at baseline and 12 months after topiroxostat administration, 46 patients $(66.7 \%)$ had sUA $\leq 6.0 \mathrm{mg} / \mathrm{dL}$. In contrast, among 30 patients whose baseline sUA level was $6.0 \mathrm{mg} / \mathrm{dL}$ or less, 26 patients (86.7\%) maintained an sUA level of $6.0 \mathrm{mg} / \mathrm{dL}$ or less after administration of topiroxostat. Of the 44 patients who had been treated with other UA-lowering drugs before the administration of topiroxostat, 12 months after the administration of topiroxostat, 32 patients $(72.7 \%$ ) had sUA levels of $6.0 \mathrm{mg} / \mathrm{dL}$ or less.

\subsection{Safety}

There were no serious adverse events after the administration of topiroxostat. Regarding the laboratory parameters, there were no significant changes in any of the parameters

Table 3 Changes in laboratory parameters at baseline and after each timepoint

\begin{tabular}{|c|c|c|c|c|c|c|c|}
\hline & Baseline & 3 months & 6 months & 9 months & 12 months & 24 months & 36 months \\
\hline AST (IU/L) & $\begin{array}{l}26.0 \pm 9.5 \\
(n=100)\end{array}$ & $\begin{array}{l}24.8 \pm 9.4 \\
(n=99)\end{array}$ & $\begin{array}{l}25.5 \pm 9.6 \\
(n=98)\end{array}$ & $\begin{array}{l}26.4 \pm 12.7 \\
(n=95)\end{array}$ & $\begin{array}{c}26.5 \pm 10.9 \\
(n=100)\end{array}$ & $\begin{array}{l}26.3 \pm 9.0 \\
(n=83)\end{array}$ & $\begin{array}{l}26.0 \pm 9.0 \\
(n=51)\end{array}$ \\
\hline ALT (IU/L) & $\begin{array}{l}19.9 \pm 11.0 \\
(n=100)\end{array}$ & $\begin{array}{l}19.9 \pm 11.2 \\
(n=99)\end{array}$ & $\begin{array}{l}19.8 \pm 10.2 \\
(n=98)\end{array}$ & $\begin{array}{l}19.9 \pm 11.3 \\
(n=95)\end{array}$ & $\begin{array}{l}20.2 \pm 12.7 \\
(n=100)\end{array}$ & $\begin{array}{l}20.0 \pm 11.2 \\
(n=83)\end{array}$ & $\begin{array}{l}18.8 \pm 9.3 \\
(n=51)\end{array}$ \\
\hline HDL-C (mg/dL) & $\begin{array}{l}52.3 \pm 13.7 \\
(n=99)\end{array}$ & $\begin{array}{l}53.0 \pm 13.5 \\
(n=98)\end{array}$ & $\begin{array}{l}54.6 \pm 15.1 \\
(n=97)\end{array}$ & $\begin{array}{l}53.6 \pm 14.0 \\
(n=94)\end{array}$ & $\begin{array}{l}53.7 \pm 13.6 \\
(n=97)\end{array}$ & $\begin{array}{l}52.8 \pm 15.0 \\
(n=80)\end{array}$ & $\begin{array}{l}54.5 \pm 16.1 \\
(n=51)\end{array}$ \\
\hline LDL-C (mg/dL) & $\begin{array}{l}96.6 \pm 33.2 \\
(n=95)\end{array}$ & $\begin{array}{l}92.6 \pm 27.3 \\
(n=95)\end{array}$ & $\begin{array}{l}89.8 \pm 28.1 \\
(n=94)\end{array}$ & $\begin{array}{l}90.7 \pm 28.0 \\
(n=91)\end{array}$ & $\begin{array}{l}99.7 \pm 105.9 \\
(n=97)\end{array}$ & $\begin{array}{l}86.8 \pm 27.9 \\
(n=79)\end{array}$ & $\begin{array}{l}87.2 \pm 26.5 \\
(n=51)\end{array}$ \\
\hline $\begin{array}{l}\text { Triglyceride } \\
(\mathrm{mg} / \mathrm{dL})\end{array}$ & $\begin{array}{l}145.6 \pm 85.3 \\
(n=99)\end{array}$ & $\begin{array}{l}142.3 \pm 79.9 \\
(n=98)\end{array}$ & $\begin{array}{l}133.8 \pm 70.3 \\
(n=97)\end{array}$ & $\begin{array}{l}140.5 \pm 72.9 \\
(n=94)\end{array}$ & $\begin{array}{l}132.9 \pm 100.2 \\
(n=99)\end{array}$ & $\begin{array}{l}129.7 \pm 69.1 \\
(n=80)\end{array}$ & $\begin{array}{l}122.9 \pm 58.7 \\
(n=51)\end{array}$ \\
\hline HbA1c (\%) & $\begin{array}{l}6.13 \pm 0.65 \\
(n=99)\end{array}$ & $\begin{array}{l}6.11 \pm 0.63 \\
(n=98)\end{array}$ & $\begin{array}{l}6.12 \pm 0.61 \\
(n=97)\end{array}$ & $\begin{array}{c}6.26 \pm 1.19 \\
(n=93)\end{array}$ & $\begin{array}{l}6.13 \pm 0.65 \\
(n=99)\end{array}$ & $\begin{array}{c}6.12 \pm 0.64 \\
(n=79)\end{array}$ & $\begin{array}{l}6.11 \pm 0.59 \\
(n=51)\end{array}$ \\
\hline BUN (mg/dL) & $\begin{array}{l}20.8 \pm 6.6 \\
(n=100)\end{array}$ & $\begin{array}{l}21.0 \pm 8.3 \\
(n=99)\end{array}$ & $\begin{array}{l}21.1 \pm 7.8 \\
(n=98)\end{array}$ & $\begin{array}{l}21.8 \pm 8.9 \\
(n=94)\end{array}$ & $\begin{array}{l}21.2 \pm 8.7 \\
(n=100)\end{array}$ & $\begin{array}{l}21.0 \pm 7.6 \\
(n=83)\end{array}$ & $\begin{array}{l}22.1 \pm 11.1 \\
(n=51)\end{array}$ \\
\hline $\begin{array}{l}\text { Serum creatinine } \\
(\mathrm{mg} / \mathrm{dL})\end{array}$ & $\begin{array}{l}1.15 \pm 0.27 \\
(n=100)\end{array}$ & $\begin{array}{l}1.15 \pm 0.31 \\
(n=99)\end{array}$ & $\begin{array}{l}1.16 \pm 0.30 \\
(n=98)\end{array}$ & $\begin{array}{l}1.16 \pm 0.37 \\
(n=95)\end{array}$ & $\begin{array}{l}1.14 \pm 0.29 \\
(n=100)\end{array}$ & $\begin{array}{l}1.20 \pm 0.34 \\
(n=83)\end{array}$ & $\begin{array}{l}1.22 \pm 0.53 \\
(n=51)\end{array}$ \\
\hline $\begin{array}{l}\text { eGFR }(\mathrm{mL} / \\
\left.\min / 1.73 \mathrm{~m}^{2}\right)\end{array}$ & $\begin{array}{l}46.8 \pm 15.3 \\
(n=100)\end{array}$ & $\begin{array}{l}46.9 \pm 14.6 \\
(n=99)\end{array}$ & $\begin{array}{l}46.7 \pm 15.6 \\
(n=98)\end{array}$ & $\begin{array}{l}47.0 \pm 15.3 \\
(n=95)\end{array}$ & $\begin{array}{l}47.1 \pm 15.9 \\
(n=100)\end{array}$ & $\begin{array}{l}45.9 \pm 14.1 \\
(n=83)\end{array}$ & $\begin{array}{l}47.3 \pm 14.5 \\
(n=51)\end{array}$ \\
\hline $\begin{array}{l}\text { Serum uric acid } \\
(\mathrm{mg} / \mathrm{dL})\end{array}$ & $\begin{array}{l}7.01 \pm 1.58 \\
(n=99)\end{array}$ & $\begin{array}{l}5.55 \pm 1.49 \\
(n=99)\end{array}$ & $\begin{array}{l}5.44 \pm 1.65 \\
(n=98)\end{array}$ & $\begin{array}{l}5.27 \pm 1.72 \\
(n=95)\end{array}$ & $\begin{array}{l}5.08 \pm 1.56 \\
(n=99)\end{array}$ & $\begin{array}{l}4.84 \pm 1.55 \\
(n=82)\end{array}$ & $\begin{array}{l}4.80 \pm 1.57 \\
(n=51)\end{array}$ \\
\hline $\begin{array}{l}\text { NT-proBNP (pg/ } \\
\text { mL) }\end{array}$ & $\begin{array}{l}347.7 \\
{[117.8-917.5]} \\
(n=79)\end{array}$ & $\begin{array}{l}441.0 \\
{[169.2-920.5]} \\
(n=79)\end{array}$ & $\begin{array}{l}437.1 \\
{[163.1-1008.0]} \\
(n=80)\end{array}$ & $\begin{array}{l}376.6 \\
{[121.9-858.2]} \\
(n=79)\end{array}$ & $\begin{array}{l}412.3 \\
{[128.3-870.8]} \\
(n=85)\end{array}$ & $\begin{array}{l}322.9 \\
{[105.3-1115.9]} \\
(n=75)\end{array}$ & $\begin{array}{l}322.0 \\
{[135.0-628.0]} \\
(n=49)\end{array}$ \\
\hline $\mathrm{CRP}(\mathrm{mg} / \mathrm{dL})$ & $\begin{array}{l}\quad 0.11 \\
{[0.08-0.27]} \\
(n=79)\end{array}$ & $\begin{array}{l}\quad 0.14 \\
{[0.07-0.23]} \\
(n=84)\end{array}$ & $\begin{array}{l}\quad 0.12 \\
{[0.06-0.26]} \\
(n=85)\end{array}$ & $\begin{array}{l}\quad 0.14 \\
{[0.07-0.35]} \\
(n=82)\end{array}$ & $\begin{array}{l}\quad 0.12 \\
{[0.07-0.27]} \\
(n=88)\end{array}$ & $\begin{array}{l}\quad 0.13 \\
{[0.07-0.29]} \\
(n=76)\end{array}$ & $\begin{array}{l}\quad 0.12 \\
{[0.06-0.22]} \\
(n=49)\end{array}$ \\
\hline
\end{tabular}

$A L T$ alanine transaminase, $A S L$ aspartate transaminase, $B U N$ blood urea nitrogen, $C R P$ C-reactive protein, $e G F R$ estimated glomerular filtration rate, $H D L-C$ high-density lipoprotein cholesterol, $L D L-C$ low-density lipoprotein cholesterol, $N T$-proBNP N-terminal pro-brain natriuretic peptide

Mean \pm standard deviation: median $(25-75 \%)$ 
other than sUA after the administration of topiroxostat (Table 3).

\section{Discussion}

This study showed that topiroxostat significantly reduced sUA levels in patients with hyperuricemia, who were mainly elderly and associated with impaired renal function. There was no significant increase in $\mathrm{sCr}$ levels after treatment with topiroxostat. Furthermore, the eGFR 6 months before the administration of topiroxostat until baseline was significantly decreased, while a decrease in eGFR was not observed after the administration of topiroxostat. These results suggest that topiroxostat has the potential to relieve the decline in renal function over time.

The primary treatment goal in patients with hyperuricemia is to decrease sUA levels and to control the levels to $6.0 \mathrm{mg} / \mathrm{dL}$ or less to prevent gout [12]. Recent studies have demonstrated that hyperuricemia is likely to be implicated in the onset and progression of CKD, alongside worsening renal function in various cohorts or community-based populations [10, 20, 21].

Chronic kidney disease progression may lead to endstage renal disease, which requires renal replacement therapy such as dialysis or kidney transplantation. Chronic kidney disease has also been reported to be associated with higher risks of death from any cause [22], cardiovascular events [23], hospitalization, and higher healthcare costs [24]. Therefore, prevention of CKD development and/or progression is a major public health issue.

It has been reported that individuals with UA levels $>5.9 \mathrm{mg} / \mathrm{dL}$ have an increased risk of a decrease in eGFR of $3 \mathrm{~mL} / \mathrm{min} / 1.73 \mathrm{~m}^{2}$ per year or greater in a longitudinal analysis [8]. In this study, during the last 6 months before treatment with topiroxostat, $\mathrm{sCr}$ slightly increased $(0.070 \mathrm{mg} / \mathrm{dL})$, and eGFR decreased by $3.45 \mathrm{~mL} /$ $\min / 1.73 \mathrm{~m}^{2}$. These changes were greater than those described above; however, they may be caused in part by the combination of hyperuricemia and risk factors for renal function, such as hypertension, dyslipidemia, and type 2 diabetes. Six months after treatment with topiroxostat, eGFR increased by only $0.18 \mathrm{~mL} / \mathrm{min} / 1.73 \mathrm{~m}^{2}(\mathrm{sCr}$ increased by only $0.010 \mathrm{mg} / \mathrm{dL}$ ). Although this is a shortterm comparison, it seems reasonable to consider that the decrease in renal function over time was suppressed by the administration of topiroxostat.

In a prospective randomized trial, allopurinol significantly suppressed the reduction in eGFR compared with that in the control group $(p=0.018)$ [25]. In a metaanalysis of 19 studies with allopurinol, a difference of 3.2 $\mathrm{mL} / \mathrm{min} / 1.73 \mathrm{~m}^{2}$ was observed in the reduction of eGFR between patients with G3 or higher CKD and the control group [26]. In the case of febuxostat, a meta-analysis of 11 studies of patients with hyperuricemia associated with CKD showed a significant reduction in sUA [27]. Simultaneously, the eGFR difference with that of the control group was not significant, coming in at $2.36 \mathrm{~mL} / \mathrm{min} / 1.73$ $\mathrm{m}^{2}$. These results indicate that XOR inhibitors are more effective than conventional therapies in suppressing the decline in renal function. In this study, suppression of declining renal function by topiroxostat administration was also observed in the patient group aged over 75 years.

Although CKD is associated with increased sUA levels, the incidence of hyperuricemia in stages G3b and G4 of CKD is 2.12 and 4.57 times higher than in stage G3a, respectively [14]. The proportion of patients in the optimal range for the sUA level according to the CKD stage (G3a, G3b, G4, and G5) has also been reported in both sexes [14]. In addition, the relationship between decreased eGFR and the risk of end-stage renal disease in patients with CKD in Japan was clearly revealed [28]. In this study, topiroxostat suppressed the decline in renal function in patients with hyperuricemia, about half of whom were switched from other XOR inhibitors. Taken together, topiroxostat may be more beneficial for the treatment of patients with hyperuricemia.

Long-term administration of UA-lowering drugs is required in patients with hyperuricemia; therefore, safety is also an important clinical problem. A total of 100 patients in this study were able to receive topiroxostat for over 12 months, and there were no adverse events or abnormal liver function values for which a causal relationship to topiroxostat could not be ruled out. The long-term (12month) efficacy and tolerability of topiroxostat have been further confirmed in an observational study conducted in over 4000 patients [29].

This study has some limitations. First, this was a retrospective single-center study, which may introduce selection bias and was evaluated in one ethnic group (Japanese). Second, there were a small number of subjects, as there were not many patients who received topiroxostat for more than 1 year at our hospital, which may limit the strength of our conclusions. However, our data can be considered "realworld" data of daily clinical practice. Third, the treatment period was comparatively short, which may explain why the eGFR did not improve over the time span measured. While some clinical data, including our study, are promising, welldesigned large-scale and long-term studies are warranted to evaluate whether topiroxostat improves renal function in patients with hyperuricemia. 


\section{Conclusions}

This study revealed that topiroxostat treatment not only reduced serum UA levels significantly, but also maintained $\mathrm{sCr}$ and eGFR in hyperuricemic patients. Importantly, these findings were obtained from elderly patients for over 1 year. Thus, topiroxostat may be a useful UA-lowering agent for elderly patients with hyperuricemia in daily clinical practice.

\section{Declarations}

Funding This study was funded by Fuji Yakuhin Co., Ltd., the manufacturer and distributor of topiroxostat.

Conflict of interest The authors have no other conflicts of interest to disclose in connection with the publication of the study results.

Ethics approval This study was approved by the Ethics Committee of Koto Hospital and was conducted in accordance with the "Ethical Guidelines for Medical Research Involving Human Subjects". The study procedures adhered to the Declaration of Helsinki and the Strengthening the Reporting of Observational Studies in Epidemiology (STROBE) statement, and the study was registered with the University Hospital Medical Information Network (UMIN000039120).

Consent to participate Written or oral patient consent was not obtained as the medical records of each patient were extracted retrospectively. The opt-out right was provided to patients when displaying the study's implementation on hospital notices.

Consent for publication Not applicable.

Availability of data and material Data used in this study are not publicly available. The anonymized dataset was on a file at Koto Hospital.

Code availability Not applicable.

Author contributions ET participated in the research design preparation and checked the statistical analysis plan. ET, HY, TT, TM, JK, and SY managed patient clinical records. ET drafted the manuscript, TK and HK reviewed the manuscript, and all authors approved the final manuscript.

Open Access This article is licensed under a Creative Commons Attribution-NonCommercial 4.0 International License, which permits any non-commercial use, sharing, adaptation, distribution and reproduction in any medium or format, as long as you give appropriate credit to the original author(s) and the source, provide a link to the Creative Commons licence, and indicate if changes were made. The images or other third party material in this article are included in the article's Creative Commons licence, unless indicated otherwise in a credit line to the material. If material is not included in the article's Creative Commons licence and your intended use is not permitted by statutory regulation or exceeds the permitted use, you will need to obtain permission directly from the copyright holder. To view a copy of this licence, visit http://creativecommons.org/licenses/by-nc/4.0/.

\section{References}

1. El Ridi R, Tallima H. Physiological functions and pathogenic potential of uric acid: a review. J Adv Res. 2017;8:487-93. https:// doi.org/10.1016/j.jare.2017.03.003.

2. Freig DI, Kang DH, Johnson RJ. Uric acid and cardiovascular risk. N Engl J Med. 2008;359:1811-21. https://doi.org/10.1056/ NEJMra0800885.

3. Borghi C, Agabiti-Rosei E, Johnson RJ, Kielstein JT, Lurbe E, Mancia G, et al. Hyperuricemia and gout in cardiovascular, metabolic and kidney disease. Eur J Intern Med. 2020;80:1-11. https:// doi.org/10.1016/j.ejim.2020.07.006 (Epub 2020 Jul 29 PMID: 32739239).

4. Sumiyoshi H, Ohyama Y, Imai K, Kurabayashi M, Saito Y, Nakamura T. Association of uric acid with incident metabolic syndrome in a Japanese general population. Int Heart J. 2019;60:830 5. https://doi.org/10.1536/ihj.18-444.

5. Johnson RJ, Nakagawa T, Jalal D, Sánchez-Lozada LG, Kang DH, Ritz E. Uric acid and chronic kidney disease: which is chasing which? Nephrol Dial Transplant. 2013;28:2221-8. https://doi.org/ 10.1093/ndt/gft029.

6. Kielstein JT, Pontremoli R, Burnier M. Management of hyperuricemia in patients with chronic kidney disease: a focus on renal protection. Curr Hypertens Rep. 2020;22:102. https://doi.org/10. 1007/s11906-020-01116-3.

7. Tada K, Maeda T, Takahashi K, Ito K, Yasuno T, Funakoshi S, et al. Association between serum uric acid and new onset and progression of chronic kidney disease in a Japanese general population: Iki epidemiological study of atherosclerosis and chronic kidney disease. Clin Exp Nephrol. 2021;25:751-9. https://doi.org/ 10.1007/s10157-021-02042-7.

8. Chonchol M, Shlipak MG, Katz R, Sarnak MJ, Newman AB, Siscovick DS, et al. Relationship of uric acid with progression of kidney disease. Am J Kidney Dis. 2007;50:239-47. https://doi. org/10.1053/j.ajkd.2007.05.013.

9. Iseki K, Ikemiya Y, Inoue T, Iseki C, Kinjo K, Takishita S. Significance of hyperuricemia as a risk factor for developing ESRD in a screened cohort. Am J Kidney Dis. 2004;44(4):642-50 (PMID: 15384015).

10. Hsu CY, Iribarren C, McCulloch CE, Darbinian J, Go AS. Risk factors for end-stage renal disease: 25 -year follow-up. Arch Intern Med. 2009;169(4):342-50. https://doi.org/10.1001/archinternmed. 2008.605.PMID:19237717;PMCID:PMC2727643.

11. Weiner DE, Tighiouart H, Elsayed EF, Griffith JL, Salem DN, Levey AS. Uric acid and incident kidney disease in the community. J Am Soc Nephrol. 2008;19:1204-11. https://doi.org/10. 1681/ASN.2007101075.

12. Hisatome I, Ichida K, Mineo I, Ohtahara A, Ogino K, Kuwabara M, et al. Japanese Society of Gout and Uric \& Nucleic Acids 2019 guidelines for management of hyperuricemia and gout. Gout Uric Nucleic Acids. 2020;44:1-40. https://doi.org/10.14867/gnamt sunyo.44.Supplement_sp-1.

13. Araumi A, Ichikawa K, Konta T, Fujimoto S, Iseki K, Moriyama $\mathrm{T}$, et al. The distribution of eGFR by age in a community-based healthy population: the Japan specific health checkups study (J-SHC study). Clin Exp Nephrol. 2021;25:1303-10. https://doi. org/10.1007/s10157-021-02107-7.

14. Sofue T, Nakagawa N, Kanda E, Nagasu H, Matsushita K, Nangaku M, et al. Prevalence of hyperuricemia and electrolyte abnormalities in patients with chronic kidney disease in Japan: a nationwide, cross-sectional cohort study using data from the Japan Chronic Kidney Disease Database (J-CKD-DB). PLoS ONE. 2020;15(10): e0240402. https://doi.org/10.1371/journal. pone. 0240402 . 
15. Vargas-Santos AB, Neogi T. Management of gout and hyperuricemia in CKD. Am J Kidney Dis. 2017;70:422-39. https://doi.org/ 10.1053/j.ajkd.2017.01.055.

16. Borghi C, Domienikarłowicz J, Tykarski, Widecka K, Filipiak $\mathrm{KJ}$, Jaguszewski MJ, et al. Expert consensus for the diagnosis and treatment of patient with hyperuricemia and high cardiovascular risk: update. Cardiol J. 2021;28:1-14. doi: https://doi.org/ 10.5603/cj.a2021.0001.

17. Hosoya T, Ohno I, Nomura S, Hisatome I, Uchida S, Fujimori S, et al. Effects of topiroxostat on the serum urate levels and urinary albumin excretion in hyperuricemic stage 3 chronic kidney disease patients with or without gout. Clin Exp Nephrol. 2014;18:876-84. https://doi.org/10.1007/s10157-014-0935-8.

18. Mizukoshi T, Kato S, Ando M, Sobajima H, Ohashi N, Naruse T, et al. Renoprotective effects of topiroxostat for hyperuricaemic patients with overt diabetic nephropathy study (ETUDE study): a prospective, randomized, multicentre clinical trial. Nephrology (Carlton). 2018;23:1023-30. https://doi.org/10.1111/nep.13177.

19. Matsuo S, Imai E, Horio M, Yasuda Y, Tomita K, Nitta K, et al. Revised equations for estimated GFR from serum creatinine in Japan. Am J Kidney Dis. 2009;53(6):982-92. https://doi.org/10. 1053/j.ajkd.2008.12.034.

20. Kamei K, Konta T, Hirayama A, Suzuki K, Ichikawa K, Fujimoto $\mathrm{S}$, et al. A slight increase within the normal range of serum uric acid and the decline in renal function: associations in a community-based population. Nephrol Dial Transplant. 2014;29:228692. https://doi.org/10.1093/ndt/gfu256.

21. Kuwabara M, Bjornstad P, Hisatome I, Niwa K, Roncal-Jimenez CA, Andres-Hernando A, Jensen T, et al. Elevated serum uric acid level predicts rapid decline in kidney function. Am J Nephrol. 2017;45(4):330-7. https://doi.org/10.1159/000464260.

22. Sud M, Tangri N, Pintilie M, Levey AS, Naimark D. Risk of end stage renal disease and death after cardiovascular events in chronic kidney disease. Circulation. 2014;130:458-65. https://doi.org/10. 1161/circulationaha.113.007106.
23. Gansevoort RT, Correa-Rotter R, Hemmelgarn BR, Jafar TH, Heerspink HJL, Mann JF, et al. Chronic kidney disease and cardiovascular risk: epidemiology, mechanisms, and prevention. Lancet. 2013;382:339-52. https://doi.org/10.1016/s0140-6736(13) 60595-4.

24. Braun LA, Sood V, Hogue S, Lieberman B, Copley-Merriman C. High burden and unmet patient needs in chronic kidney disease. Int J Nephrol Renovasc Dis. 2012;5:151-63. https://doi.org/10. 2147/ijnrd.s37766.

25. Goicoechea M, de Vinuesa SG, Verdalles U, Ruiz-Caro C, Ampuero J, Rincón A, et al. Effect of allopurinol in chronic kidney disease progression and cardiovascular risk. Clin J Am Soc Nephrol. 2010;5:1388-93. https://doi.org/10.2215/cjn.01580210.

26. Kanji T, Gandhi M, Clase CM, Yang R. Urate lowering therapy to improve renal outcomes in patients with chronic kidney disease: systematic review and meta-analysis. BMC Nephrol. 2015;16:58. https://doi.org/10.1186/s12882-015-0047-z.

27. Lin TC, Hung LY, Chen YC, Lo WC, Lin CH, Tam KW, et al. Effects of febuxostat on renal function in patients with chronic kidney disease: a systematic review and meta-analysis. Medicine. 2019;98: e16311. https://doi.org/10.1097/md.0000000000016311.

28. Matsushita K, Chen J, Sang Y, Ballew SH, Shimazaki R, Fukagawa M, et al. Risk of end-stage renal disease in Japanese patients with chronic kidney disease increases proportionately to decline in estimated glomerular filtration rate. Kidney Int. 2016;90:1109-14. https://doi.org/10.1016/j.kint.2016.08.003.

29. Ishikawa T, Maeda T, Hashimoto T, Nakagawa T, Ichikawa K, Sato $\mathrm{Y}$, et al. Long-term safety and effectiveness of the xanthine oxidoreductase inhibitor, topiroxostat in Japanese hyperuricemic patients with or without gout: a 54-week open-label, multicenter, post-marketing observational study. Clin Drug Investig. 2020;40:847-59. https://doi.org/10.1007/s40261-020-00941-3. 